\title{
A Study to Evaluate Sevoflurane With or Without Nitrous Oxide and to Compare It with Propofol as Induction Agent- A Randomized Clinical Trial
}

\author{
Supratim Dasgupta ${ }^{1}$, Babita Agrawal ${ }^{2}$, Priyadershini Rangari ${ }^{3}$ \\ ${ }^{1,2}$ Assistant Professor, Department of Anaeshtesiology, Sri Shankaracharya Medical College, Bhilai, Durg, Chhattisgarh, ${ }^{3}$ Assistant Professor, Department \\ Of Dentistry, Sri Shankaracharya Medical College, Bhilai, Durg, Chhattisgarh.
}

\section{Abstract}

Background: All intravenous anaesthetic agents have drawbacks which are related to the particular agent used; though common to all is danger of loss of control of airway. Volatile agents are not suitable for gaseous induction as they are irritating to the airways. Sevoflurane is suitable for inhalational induction because of its low blood gas solubility and its non irritant effect on airways even in high concentration. Objectives: To evaluate sevoflurane with addition of $63 \%$ nitrous oxide for induction in adults, and to compare sevoflurane (with or without nitrous oxide) with Propofol as induction agent. Subjects and Methods: A total of one hundred and fifty patients of age between 20-40 years were taken and divided into three groups of fifty each. In group I, patients were induced with sevoflurane $8 \%$ in oxygen in group II, patients were induced with sevoflurane (8\%) with $63 \% \mathrm{~N}_{2} \mathrm{O}$ in $\mathrm{O}_{2}$ and in group III, induction was carried out with Propofol. Results: Mean time of loss of eyelash reflex and jaw relaxation was statistically significant in all groups. The presence of breath holding amongst all the three groups found to be significant. The difference in oxygen saturation was not significant between group I and II but significant in group II and III. The slightly slower induction time with sevoflurane as compared to Propofol can be offset by reduced incidence of breath holding and involuntary movements. Conclusion: From this study it can be concluded that $8 \%$ sevoflurane carried in nitrous oxide and oxygen is a rapid, reliable and safe method for the induction of anaesthesia when a vital capacity technique is used.

Keywords: Induction Agent, Nitrous Oxide (N2O), Oxygen (O2), Propofol, Sevoflurane.

Corresponding Author: Dr. Babita Agrawal, Sri Shankaracharya Medical College, Bhilai, Durg, Chhattisgarh.

Received: November 2019

Accepted: November 2019

\section{Introduction}

The practice of anaesthesia started with inhalational agents in 1840 which remained the standard technique for induction of anaesthesia for over one hundred years. Induction of anaesthesia with inhalational anaesthetic agents was abandoned because it was slow, smelly, caused excessive salivation and resulted in coughing and vomiting. An increasing interest in intravenous anaesthetic technique has resulted from the availability of more efficacious intravenous drugs and drawbacks of inhalational agents like toxicity, high cost and anaesthetic gas pollution in the operating and recovery room. ${ }^{[1,2]}$

In 1920s, tribromethanol and barbiturates were used. During the 1930s and 1940s, hexobarbitone became very popular, despite its limitation like muscle movement. During the same period it was appreciated that thioderivatives of diallyl barbiturates were valuable hypnotics. Since late 1930s, thiopentone remained the most popular intravenous anaesthetic agent despite prolonged duration of action and delayed recovery. ${ }^{[3]}$

In 1980s, Propofol was introduced in clinical practice which has a definite advantage of having faster recovery along with its antiemetic effect. However its negative inotropic and respiratory depressant effect is more than that of thiopentone. In situations where rapid induction and rapid recovery is desirable, Propofol remains the drug of choice. ${ }^{[4]}$

Inhalational induction may be preferable in paediatric patients, in adult patients with needle phobia, in patients where there is a difficulty in establishing intravenous line. However, the principle indication for inhalational induction in adults is anticipated difficulty in control of the airway. Inhalational agents are free from hangover effect and risk of anaphylaxis is also avoided. ${ }^{[8]}$

Halothane was the first halogenated hydrocarbon which was brought into clinical practice by Bryce-Smith and O'Brien in 1956. ${ }^{[9,10]}$ It is non combustible, apparently non-toxic, sweet smelling and allows a rapid, clear headed recovery as compared to older anaesthetics. It suffers from many drawbacks most important of which are myocardial depression and halothane hepatitis on repeated exposure. Between 1959 and 1966, Terrell and his associates synthesized more than 700 compounds in a programme intended specifically to produce a better inhalational anaesthetic agent. Close on the heels of isoflurane and 
enflurane, another compound desflurane was invented. Enflurane has poor induction characteristics and potential to cause seizures. $^{[11,12]}$

Isoflurane has some definite advantages over halothane and enflurane like haemodynamic stability and being nonepileptogenic.

Sevoflurane is related structurally to isoflurane and enflurane and shares many of the physical properties of these drugs. The low blood: gas solubility of sevoflurane permits rapid induction of anaesthesia as it rapidly equilibrates with the inspired concentration. In addition sevoflurane is pleasant smelling and relatively non-irritant to the airways permitting a high delivered concentration to be inhaled without side effects or discomfort. ${ }^{[13-18]}$

Although inhalational induction is the route of choice for anaesthetizing neonates and children but under certain situations like needle phobias and potential difficult airways, inhalational induction is desirable even in adults. Halothane has been the agent of choice till recently but with the introduction of sevoflurane in anaesthesia practice, inhalational induction seems more favourable with sevoflurane owing to its pleasant smell and low blood: gas solubility. Keeping this in background, we studied the induction characteristics of sevoflurane with or without N20 in adults and compared it with the most prevalent intravenous induction agent propofol.

This study was performed to evaluate sevoflurane with addition of $63 \%$ nitrous oxide for induction in adults, and to compare sevoflurane (with or without nitrous oxide) with propofol as induction agent.

\section{Subjects and Methods}

The present study was conducted in the Department of Anaeshtesiology, Sri Shankaracharya Medical College, Bhilai, Durg, Chhattisgarh, India. A total of 150 patients in the age group of 20-40 years of either sex, scheduled for short elective surgical procedure under general anaesthesia where use of LMA was considered appropriate, were included in the study.

Patients having any neurological disease, history of malignant hyperthermia in the family, preexisting renal insufficiency, known hypersensitivity to halogenated hydrocarbons or propofol, upper respiratory tract infection, receiving sedatives or analgesics chronically, hyperactive airways, smokers, pregnant patients and lactating mothers were excluded from the present study.

Patients were examined one day prior to surgery and a complete history of any past or present illness was obtained with special emphasis on: History suggestive of upper respiratory tract infection, past history of cardiac problem, any history of drug sensitivity especially to lignocaine/ Propofol was noted. All patients' were subjected to complete general physical as well as systemic examination. Routine laboratory investigations were carried out along with any other specific investigations as required keeping in view the surgical condition of the patient. After determining the patient fitness for anaesthesia, procedure was explained to all the patients and written informed consent was obtained for participation in the study in a given set of proforma. No premedication was given.

In the operation theatre, after recording baseline blood pressure, pulse rate and haemoglobin oxygen saturation (SpO2), an intravenous line was secured in patient's non dominant hand. All patients were explained about the procedure and instructions regarding vital capacity breath and holding of a water filled $20 \mathrm{ml}$ glass syringe by its nozzle between his thumb and index finger for as long as he could were given. Patients were then randomly allocated to any of the three groups. Randomization was done by drawing a coded envelope from a box containing 150 envelops.

- Group I ( $\mathrm{n}=50)$ sevoflurane $(8 \%)$ in $100 \%$ O2 by face mask using Bain's circuit for induction of anaesthesia.

- Group II $(n=50)$ sevoflurane $(8 \%)$ and $63 \% \mathrm{~N} 2 \mathrm{O}$ in oxygen by face mask using Bain's circuit.

- Group III $(\mathrm{n}=50)$ injection propofol $1 \%$ at a rate of 0.5 $\mathrm{ml} / \mathrm{sec}$. until the end points of induction were achieved.

Anaesthesia technique- $2 \mathrm{ml}$ of $1 \%$ lignocaine (preservative free) was administered in all patients. In group I the circuit was primed with 8 lit of oxygen and sevoflurane $(8 \%)$ and in group II it was primed with 3 lit of $\mathrm{O} 2,5$ lit of $\mathrm{N} 2 \mathrm{O}$ and $8 \%$ sevoflurane.

The circuit the desired anaesthetic gas mixture was allowed to run through the Bain's circuit with reservoir bag collapsed. During this period the patient end of circuit remained open. After thirty seconds the patient end was closed and the reservoir bag was allowed to fill to its capacity without tension. In group III no priming of the circuit was done.

Following vital capacity breath, patients were allowed to resume spontaneous respiration and to breathe the same anaesthetic mixture till the dropping of weighted syringe, abolition of eye lash reflex and adequate jaw relaxation. The timing was recorded.

In group I and II, the timing were as follows:

- $\mathrm{Td}=$ time of dropping the weighted syringe

- $\mathrm{Te}=$ time of loss of eyelash reflex

- $\mathrm{Tj}$ = time of jaw relaxation

- Dd, De and Dj were the doses of propofol in mgm at the above mentioned end points respectively.

In group III while breathing room air propofol $1 \%$ was administered at a rate of $0.5 \mathrm{ml} / \mathrm{sec}$ to all the patients and the time and dose was recorded at the time when: patient dropped a weighted syringe, the eyelash reflex got abolished, there was jaw relaxation.

In all the groups a well lubricated proper sized LMA was introduced after adequate relaxation of jaws was achieved and anaesthesia was maintained using $\mathrm{O} 2, \mathrm{~N} 2 \mathrm{O}$, halothane $0.5 \%$ with or without muscle relaxants as dictated by the surgical procedure. The occurrence of excitatory phenomenon (movements, myoclonus); or respiratory problems e.g. cough, breath hold in laryngospasm, bronchospasm, excessive salivation or any other adverse effect, if any was noted during induction as well as while putting the LMA. If the insertion of LMA was not possible on first attempt it was labeled as failed. In these patients the LMA was placed using muscle relaxant. Thereafter anaesthesia was maintained using nitrous oxide, oxygen and halothane with or without muscle relaxant as dictated by the requirement of surgical procedure.

In each patient noninvasive blood pressure, pulse rate and 
$\mathrm{SpO} 2$ were recorded just before induction, just after induction, after insertion of LMA and at one minute interval for five minutes thereafter. ECG was monitored throughout the study period for occurrence of any arrhythmias. Blood pressure was recorded by Riva Roci method. Pulse rate, ECG and $\mathrm{SpO} 2$ was monitored. The timings of recordings of the above parameters were as follows:

- $\mathrm{Vi}=$ Before induction

- $\mathrm{VBL}=$ Just before LMA insertion

- $\mathrm{VAL}=$ Just after LMA insertion

- $\mathrm{V}=$ One minute after LMA insertion

- $\mathrm{V} 2$ = Two minutes after LMA insertion

- $\mathrm{V} 3=$ Three minutes after LMA insertion

- V4 = Four minutes after LMA insertion

- $\mathrm{V} 5$ =Five minutes after LMA insertion

Patient's performance of the maneuvers was categorized as satisfactory or non satisfactory.

All the data was compiled in the proforma attached. At the completion of study, the results were analysed using chi square, $\mathrm{t}$-test, z-test and ANOVA wherever appropriate.

\section{Results}

Distribution of age, sex and weight is shown in following [Table 1].
Mean age of patients was $26.42+6.35$ years in group I, $28.80 \pm 7.40$ years in group II and $27.62 \pm 6.77$ years in group III, the difference in the mean age of patients in group I, II and III was found to be statistically insignificant ( $p>0.05$ ). Statistically using chi square test no significant difference was found in the sex incidence in all three groups ( $p>0.05)$. The difference in the mean weight of the patients in all the three groups was found to be insignificant $(p>0.05)$.

The patients underwent short surgical procedures. The distribution of patients according to various types of surgery is shown in [Table 2].

Mean time of dropping of weighted syringe was $58.30 \pm 10.88$ in group I, 54,88 \pm 10.68 in group II, while in group III, it was $29.38 \pm 2.68$, the difference in mean time of dropping of weighted syringe was significant. When compared in between groups, there was no statistically significant difference between group I and II ( $p>0.05)$.

Mean time of loss of eyelash reflex was $70.36 \pm 11.00$ seconds in group I, $66.16 \pm 11.45$ seconds in group II and $32.48 \pm 2.48$ seconds in group III. The difference in mean time of loss of eye lash reflex in the 3 groups was significant.

Mean time of jaw relaxation was $139.86 \pm 16.46$ seconds in group I, 131.06 \pm 16.93 seconds in group II and $35.44 \pm 2.70$ seconds in group III. The difference in mean time of jaw relaxation in the 3 groups was found to be significant.

Table 1: Demographic distribution

\begin{tabular}{|c|c|c|c|c|c|c|c|}
\hline \multirow[t]{2}{*}{ Group } & \multirow[t]{2}{*}{ No. of patients } & \multicolumn{2}{|l|}{ Age (years) } & \multirow[t]{2}{*}{ Males \% } & \multirow[t]{2}{*}{ Females \% } & \multicolumn{2}{|c|}{ Weight (kg) } \\
\hline & & Mean \pm SD & Range & & & Mean \pm SD & Range \\
\hline I & 50 & $26.42 \pm 6.35$ & $20-40$ & $36(72)$ & $14(28)$ & $58.18 \pm 5.13$ & $45-75$ \\
\hline II & 50 & $28.80 \pm 7.40$ & $20-40$ & $35(70)$ & $15(30)$ & $59.18 \pm 6.29$ & $45-70$ \\
\hline III & 50 & $27.62 \pm 6.77$ & $20-40$ & $34(68)$ & $16(32)$ & $58.16 \pm 5.01$ & $45-70$ \\
\hline
\end{tabular}

Table 2: Distribution of patients according to surgery

\begin{tabular}{|c|c|c|c|c|}
\hline \multirow[t]{2}{*}{ Diagnosis } & \multirow[t]{2}{*}{ Operation } & \multicolumn{3}{|c|}{ No. of patients } \\
\hline & & I & II & III \\
\hline Varicocele & Varicocelectomy & 6 & 6 & 6 \\
\hline Varicose veins & Multiple ligation & 2 & 3 & 3 \\
\hline Undescended testis & Orchiopexy & 4 & 1 & 4 \\
\hline Growth bladder & Cystoscopy & 1 & 2 & - \\
\hline Hemorrhoids & Haemorrhoidectomy & 2 & 2 & 5 \\
\hline Cervical lymphadenopathy & Excision & 3 & - & 2 \\
\hline Appendicitis & Appendicectomy & 3 & 3 & 1 \\
\hline Fistula in ano & Fistulectomy & 3 & 3 & 2 \\
\hline Breast lesions & Excision & 7 & 9 & 7 \\
\hline Neurofibroma/ lymphoma & Excision & 2 & 2 & 4 \\
\hline Inguinal hernia & Herniorrhaphy & 6 & 11 & 10 \\
\hline Hydrocele & Eversion of sac & 4 & - & 6 \\
\hline Gynaecomastia & Excision & 2 & 2 & - \\
\hline Old case of burns & Split skin grafting & 2 & 2 & 1 \\
\hline Epigastric hernia & Repair & 2 & 3 & 1 \\
\hline Testicular tumor & Orchidectomy & 1 & 1 & - \\
\hline Gangrene & Finger Amputation & - & - & 1 \\
\hline Sebaceouscyst & Excision & - & - & 1 \\
\hline
\end{tabular}

Table 3: Mean time of dropping of weighted syringe, eye lash reflex and jaw relaxation.

\begin{tabular}{|c|c|c|c|c|c|c|c|}
\hline \multirow[t]{2}{*}{ Group } & \multirow[t]{2}{*}{$\begin{array}{l}\text { No. of } \\
\text { patients }\end{array}$} & \multicolumn{2}{|c|}{$\begin{array}{l}\text { Time of dropping of weighted } \\
\text { syringe (in seconds }\end{array}$} & \multicolumn{2}{|c|}{$\begin{array}{l}\text { Time of loss of eye lash reflex (in } \\
\text { seconds) }\end{array}$} & \multicolumn{2}{|c|}{ Time of jaw relaxation (in seconds) } \\
\hline & & Mean (SD) & Range & Mean (SD) & Range & Mean (SD) & Range \\
\hline I & 50 & $58.30 \pm 10.88$ & $30-80$ & $70.36 \pm 11.00$ & $40-105$ & $139.86 \pm 16.46$ & $95-180$ \\
\hline II & 50 & $54.88 \pm 10.68$ & $30-70$ & $66.16 \pm 11.45$ & $40-105$ & $131.06 \pm 16.93$ & $105-180$ \\
\hline III & 50 & $29.38 \pm 12.68$ & $25-34$ & $32.48 \pm 2.48$ & $28-38$ & $35.44 \pm 2.70$ & $31-42$ \\
\hline \multirow{2}{*}{$\begin{array}{ll}\text { Dose } \\
\text { propofol }\end{array}$} & $\mathrm{mg} / \mathrm{kg}-1$ & $146.41 \pm 12.37$ & $120-160$ & $162.71 \pm 12.00$ & $140-180$ & $177.55 \pm 13.39$ & $155-210$ \\
\hline & Mean & \multicolumn{2}{|l|}{2.52} & \multicolumn{2}{|l|}{2.76} & \multicolumn{2}{|l|}{2.94} \\
\hline
\end{tabular}


Dose of propofol required for dropping of weighted syringe when compared statistically, the difference in the doses was significant.

Mean dose of propofol required for dropping of weighted syringe is $2.52 \pm 0.2 \mathrm{mg} \mathrm{kg}-1$ for achieving loss of eyelash reflex was $2.7610 .4 \mathrm{mg} \mathrm{kg} 1$, for achieving the jaw relaxation was $2.9410 .2 \mathrm{mg} \mathrm{kg.-1}$

According to Table 5, incidence of breath holding was 8 in group I while it was 15 in group II and 24 in group III. The presence of breath holding amongst all the three groups found to be significant ( $p<0.05)$. Ten patients had movements on insertion of LMA, in group I, whereas only 2 patients moved in group II and 15 in group III. The presence or absence of movements amongst all the three groups was compared statistically using chi square test and found to be significant $(\mathrm{p}<0.01)$.

The mean oxygen saturation at different time intervals is depicted in Table 6. It increased at V, V2t V3, V4 and V5 intervals and this increase was significant when compared with baseline at Vi using paired t-test. In group II, oxygen saturation increased after induction at VBL and also after
LMA insertion at VAL and this increase was significant. It increased at V1 (V2, V3, V4 and V5 intervals and this increase was significant when compared with baseline at $\mathrm{V}$, using paired t-test. In group III, oxygen saturation decreased after induction at VBL, but this decrease was statistically insignificant when compared with baseline at $\mathrm{V}$, using paired t-test.

At VAL, the difference in oxygen saturation was not significant between group I and II and also between group I and group III using unpaired t-test but this difference was significant between group II and III.

Table 4: Distribution of patients according to Breath holding and movements

\begin{tabular}{|l|l|l|l|l|}
\hline \multirow{2}{*}{ Group } & \multicolumn{3}{|l|}{ Breath holding } & Movements \\
\cline { 2 - 5 } & Present & Absent & Present & Absent \\
\hline I & 8 & 42 & 10 & 40 \\
\hline II & 15 & 35 & 2 & 48 \\
\hline III & 24 & 26 & 15 & 35 \\
\hline
\end{tabular}

Table 5: Observations of oxygen saturation at different time intervals.

\begin{tabular}{|l|l|l|l|l|l|l|l|l|}
\hline Group & Vi & VBL & VAL & V1 & V2 & V3 & V4 & V5 \\
\hline I & $99.18 \pm 1.69$ & 99.7410 .44 & $99.80 \pm 1.14$ & $99.94 \pm 0.31$ & $99.84 \pm 0,51$ & $99.92+0.34$ & $99.96 \pm 0.28$ & $100.0 \pm 00$ \\
\hline II & $99.48 \pm 0.50$ & $99.72 \pm 10.45$ & $99.98 \pm 10.14$ & $100.00 \pm 00$ & $99.98 \pm 10.14$ & $99.98 \pm 10.14$ & $100.00 \pm 00$ & $100.0 \pm 00$ \\
\hline III & $99.04 \pm 0.20$ & $98.98 \pm 10.98$ & $99.00 \pm 11.23$ & $99.60 \pm 10.83$ & $100.00 \pm 100$ & $100.00 \pm 100$ & $100.00 \pm 00$ & $100.0 \pm 00$ \\
\hline
\end{tabular}

\section{Discussion}

The present work was conducted to study induction characteristics of sevoflurane alone and in combination with nitrous oxide and compared it with propofol induction in adults undergoing elective surgery in the Department of Anaeshtesiology, Sri Shankaracharya Medical College, Bhilai, Durg, Chhattisgarh, India. The study was carried out in Mean age in all the three groups was comparable when analysed statistically $(p>0.05)$. In this study, patients in group I and II were induced with vital capacity breath technique and for this technique patient cooperation is absolute necessity. Likewise no statistical difference was found as regards to weight of the patients in all the three groups. Male predominance was seen in all the three groups. No premedication was used as performance of the vital capacity breath could be altered by its use and dose requirement of propofol can also be affected by its use. Single breath induction or vital capacity rapid inhalational induction (VCRII) was demonstrated by Dashfield et al, ${ }^{[26]}$ in 200 patients, who were instructed to take a vital capacity breath of $4 \%$ halothane in 02 and to hold it in lungs for 30-90 seconds until loss of consciousness. The VCRII technique was found to have certain advantages over conventional inhalational and intravenous induction of anaesthesia, like prompt induction without a prolonged excitatory phase and smooth recovery. Yurino and Kimura, ${ }^{[21]}$ used this technique with sevoflurane for induction of anaesthesia with $7.5 \%$ sevoflurane in $\mathrm{N} 20$ and $\mathrm{O} 2$. A single breath technique was made akin to that of intravenous bolus injection and they demonstrated that it is associated with fewer adverse airway events.

In this study in group I and group II, the circuit was primed with the desired anaesthetic gas mixture (i.e. $8 \%$ sevoflurane in oxygen in group I and $8 \%$ sevoflurane in $63 \%$ nitrous oxide and oxygen in group II) by allowing it to run through Bain's circuit with reservoir bag collapsed for thirty seconds. Since our institution does not have anaesthetic gas analyzer, vaporizer setting was taken as a guide of delivered concentration. To make sure that desired concentration of sevoflurane is delivered to the patient, priming of circuit was carried out using 8 lit min- 1 of anaesthetic gas mixture for 30 seconds with reservoir bag collapsed.

In group III, propofol (1\% solution) mixed with $2 \mathrm{ml}$ of $1 \%$ lignocaine was given at the rate of $0.5 \mathrm{ml} / \mathrm{sec}$, till various endpoints of induction were achieved.

Injection lignocaine $2 \mathrm{ml}$ of $1 \%$ solution (preservative free) was given in group I and II also just before induction to make the study comparable. Loss of eyelash reflex, dropping of $20 \mathrm{ml}$ weighted syringe and jaw relaxation were taken as induction end points.

In our study mean time of dropping of weighted syringe was significantly less in propofol group $(29.38 \pm 2.68$ seconds $)$ as compared to sevoflurane groups. Among sevoflurane groups time taken to achieve this end point was more in patients induced with sevoflurane in oxygen $(58.30 \pm 10.88$ seconds $)$ as compared to patients induced with sevoflurane in N20 and $\mathrm{O} 2,(54.88 \pm 10.68$ seconds), though not significant (Group I $>$ Group II > Group III).

A similar study conducted by Thwaites et al, ${ }^{[25]}$ compared induction characteristics of sevoflurane with propofol in 102 patients in two groups of 51 each and considered dropping of 
weighted syringe as end point. They also found that induction with propofol is rapid than with sevoflurane which is similar to our observations. But in their study they observed that the time to achieve dropping of weighted syringe was more than that observed in our study $(57 \pm 11$ vs $29.38 \pm 2.68$ seconds). It may be because of slower rate of injection of $1 \%$ propofol used by them (16-18 $\mathrm{ml}$ min'1). Time to achieve this end point in patients induced with sevoflurane and $\mathrm{N} 2 \mathrm{O}$ and $\mathrm{O} 2$ was more in their study than that observed in our study ( $84 \pm 24$ vs $54.88 \pm 10.68$ seconds). It may be because they used tidal breath technique for induction whereas we used vital capacity breath technique which is known to enhance induction.

Our results are in contrast to those observed by Dashfield et al. ${ }^{[26]}$ In their study, they observed that time of dropping of weighted syringe was significantly longer in propofol group $(92 \mathrm{sec})$ than in sevoflurane group $(75 \mathrm{sec})$. It may be because they used slower rate of propofol injection $(20 \mathrm{ml}$ min-1). Further in their study, time to achieve this end point in sevoflurane group was longer than observed in our study (75 sec vs $54.48 \mathrm{sec}$ ). These conflicting results may be due to our patient population being younger (average age 28 years vs 40 years) and moreover we did not administer injection fentanyl. Both the above factors are known to affect performance of vital capacity breath.

Again in their study the time to achieve this end point in propofol group was significantly longer than observed in our study $(29.50 \mathrm{sec})$. This may be explained on the basis that we used different rate of propofol injection.

In our study, the time to achieve loss of eyelash reflex was longest in patients induced with $8 \%$ sevoflurane in oxygen (group I) followed by those induced by combination of sevoflurane in $\mathrm{N}_{2} \mathrm{O}$ and $\mathrm{O}_{2}$ (group II) and was least in patients induced with propofol (group III) (Group I > Group II $>$ Group III).

In a study by Hall et al, ${ }^{[24]}$ time to achieve loss of eyelash reflex in patients induced with $8 \%$ sevoflurane in 02 was 71 \pm 37 seconds and in patients induced with $8 \%$ sevoflurane in $\mathrm{N} 2 \mathrm{O}$ and $\mathrm{O} 2$ was $61 \pm 24$ seconds which is comparable to the results of our study. Although they also observed that time to abolish eyelash reflex was least in the propofol group than in sevoflurane groups, but this time in their study was much more as compared to ours ( $60 \pm 25$ vs $32.48 \pm 2.48 \mathrm{sec}$ ).

Administering incremental doses, assessing the effect and followed by another incremental dose if need be must have consumed more time than that of our methodology where 5 $\mathrm{mg} / \mathrm{sec}$ propofol was continued to be administered till the end point was achieved. After this propofol infusion at rate of $12 \mathrm{mg} \mathrm{kg}-1 \mathrm{hr}-1$, which is much slower as compared to our study, was started. Authors however do not clarify whether the infusion was started just after cessation of finger tapping or after the loss of eye lash reflex which takes more time.

Our results are also similar to study by Smith et al. ${ }^{[23]}$ This time was more than what has been observed in our study which is probably because of lower fixed dose $(2 \mathrm{mg} \mathrm{kg}-1)$ used by them followed by inhalational anaesthetics. Probably because of this reason the variation in induction time was also observed to be large in their propofol group.

Further time to achieve loss of eyelash reflex with sevoflurane $8 \%$ in oxygen and combination of sevoflurane and $\mathrm{N}_{2} \mathrm{O}$ and $\mathrm{O}_{2}$ was less in our study as compared to study by Smith et al. ${ }^{[23]}$ This is because the patients in their study were induced with $5 \%$ sevoflurane in $\mathrm{N}_{2} \mathrm{O}$ and $\mathrm{O}_{2}$. Moreover in our study patients were induced using single vital capacity breath whereas in their study they coined tidal breath technique.

Our results are in contrary to study by Sivalingam et al. ${ }^{[27]}$ They observed longer time to achieve loss of eyelash reflex with propofol (46.4 seconds) than with sevoflurane in $\mathrm{N}_{2} \mathrm{O}$ and $\mathrm{O}_{2}$ (34.6 seconds). Our results are in contrast to study by Dashfield et al. ${ }^{[26]}$ They observed longer time to achieve loss of eyelash reflex in propofol group (92 sec) than in sevoflurane group (54 sec). It may be explained on the basis that they used different rate of propofol injection. Further they achieved loss of eyelash reflex earlier in sevoflurane group as compared to ours. These conflicting results may be explained by the fact that eyelash reflex is not known to be definite end point. Moreover in propofol group, they used different rate of injection.

Our results are in contrary to study by Molloy et al. ${ }^{[28]}$ They observed longer time to achieve loss of eyelash reflex with propofol $(44 \mathrm{sec})$ than with sevoflurane in $\mathrm{N}_{2} \mathrm{O}$ and $\mathrm{O}_{2}(25$ sec).

The mean time of jaw relaxation was least in propofol group; it was higher in sevoflurane $+\mathrm{N}_{2} \mathrm{O}$ in comparison to propofol group but was maximum in patients induced with sevoflurane and oxygen (Group I > Group II Group III).

Time to achieve this end point was shorter in Propofol group $(35.44 \pm 2.70 \mathrm{sec})$ in our study than observed by Hall et al, ${ }^{[2]}$ $(109 \pm 25$ seconds). It may again be because the rate of propofol administration was slower $(12 \mathrm{mg} / \mathrm{kg} / \mathrm{hr}-1)$ following initial dose of $3 \mathrm{mg} \mathrm{kg}-1$ over 30 seconds. Moreover number of patients in their study was also small. Number of patients who had episodes of breath holding was 8 in sevoflurane in $\mathrm{O}_{2}$ group, 15 in sevoflurane in $\mathrm{N}_{2} \mathrm{O}$ and $\mathrm{O}_{2}$ group and 24 in propofol group. The more incidence of breath holding in propofol group as observed in our study is supported by Thwaites et al, ${ }^{[25]}$ who observed that $65 \%$ of patients in propofol group had episodes of breath holding. Breath holding episode were also observed in study by Hall et $a l,{ }^{[24]}$ and were significantly more when induction was achieved with sevoflurane or combination of sevoflurane with $\mathrm{N}_{2} \mathrm{O}$ as compared to induction with Propofol. But in another study by Smith et al, ${ }^{[23]}$ no episode of breath holding was observed in patients induced with sevoflurane whereas only one patient had apnoea in propofol group.

In our study, number of patients in whom movement was observed on LMA insertion was less in patients induced with combination of sevoflurane and $\mathrm{N}_{2} \mathrm{O}$ and $\mathrm{O}_{2}$ than patients induced with Propofol or with $8 \%$ sevoflurane in oxygen. Our results were similar to study by Hall et $\mathrm{al}_{,[24]}$ and Sivalingam et al. ${ }^{[27]}$ This may be because they have induced patients using precalculated dose of $2.5 \mathrm{mg} \mathrm{kg}-1$ over 45 seconds. Ten patients out of 25 showed movements on insertion of LMA in sevoflurane in $\mathrm{N}_{2} \mathrm{O}$ and $\mathrm{O}_{2}$. In another study by Molloy et al28 they observed equal incidence of movements in both sevoflurane (28 out of 44) and propofol (30 out of 44) group of patients during insertion of LMA in comparison to 2 out of 50 patients in sevoflurane group and 15 out of 50 patients in propofol group in our study. These conflicting results may be explained on the basis that they 
may have attempted LMA insertion earlier in sevoflurane group i.e. 1 minute after loss of eyelash reflex $(85 \mathrm{sec})$ whereas in propofol group, they administered lower dose. No patient in our study had cough, laryngospasm, bronchospasm or excessive salivation during induction and during insertion of LMA. Other studies by Smith et al, ${ }^{[23]}$ Thwaites, and Yurino and Kimura, ${ }^{[21]}$ observed no incidence of above complications during induction. In a study by Hall et al, ${ }^{[24]}$ incidence of cough was more when the patients were induced with propofol than with sevoflurane.

In another study by Sivalingam, ${ }^{[23]}$ laryngospasm was observed during insertion when the patients were induced with propofol or with sevoflurane. However, the incidence was low and severity of laryngospasm was mild. In a separate study by Molloy et al, ${ }^{[28]}$ eleven patients out of 44 in propofol group and ten patients out of 44 experienced coughing and laryngospasm during insertion of LMA. In our study above complications were not observed because of stringent exclusion criteria in choosing our patient population.

In this study, we observed an increase in pulse rate in all the patients after induction which further increased after insertion of LMA. After that it decreased and dropped to baseline in sevoflurane groups but never dropped to baseline in propofol group. Our results are similar to those observed by Hall et $\mathrm{al}^{[24]}$ and our results were contrary to Smith et $\mathrm{al}^{[23]}$ who did not observe much difference in HR after propofol. This may be because of the lower dose of propofol used by them. Our results were similar to those observed by Sivalingam et al. ${ }^{[27]}$ They found that there was increase in pulse rate in both sevoflurane and propofol group that nearly dropped to baseline in both the groups.

In our study we observed a fall in systolic as well as diastolic blood pressure in all the groups after induction which transiently increased after LMA insertion. Thereafter again it decreased till five minutes after LMA insertion. Fall in diastolic pressure was more in sevoflurane group as compared to propofol. Our results are similar to the study by Sivalingam et al, ${ }^{[27]}$ and Smith et al, ${ }^{[23]}$ and also comparable to those observed in a study by Hall et al. ${ }^{[24]}$

In our study, there was no incidence of fall in oxygen saturation below $96 \%$ in any group. In all the groups, the oxygen saturation increased after insertion of LMA, it increased to $100 \%$ at 5 minutes in all the groups. Our results are similar to those observed by Thwaites et al, ${ }^{[25]}$ and those by Sivalingam et al. ${ }^{[27]}$ Our results are also similar to those observed by Yurino and Kimura. ${ }^{[21]}$ They also observed that oxygen saturation increased slightly after the application of anaesthetic mask. The patients in sevoflurane group found the smell of sevoflurane pleasant except the two in sevoflurane in oxygen group who found the smell unpleasant. Patients in all the groups were willing to undergo the same procedure again 9 except the same two patients in sevoflurane in $\mathrm{O}_{2}$ group who did not like the induction procedure.

Our results are comparable to those of Yurino and Kimura, ${ }^{[20]}$ and contrary to those observed by Thwaites et al. ${ }^{[25]}$ In this study 7 patients out of 51 described induction by sevoflurane as unpleasant and significantly more patients (24\%) were unwilling to receive the sevoflurane induction again. This may be attributed to tidal breath technique of induction whereas in our study we employed vital capacity breath for induction.

\section{Conclusion}

From this study it can be concluded that $8 \%$ sevoflurane carried in nitrous oxide and oxygen is a rapid, reliable and safe method for the induction of anaesthesia when a vital capacity technique is used. The slightly slower induction time with sevoflurane as compared to propofol can be offset by reduced incidence of breath holding and involuntary movements. Although the time taken for induction is significantly faster with the propofol but the above technique can safely be used as an alternative to intravenous induction in patients with needle phobias or difficult intravenous access.

\section{References}

1. Goresky GV, Muir J. Inhalation induction of anaesthesia. Can J Anaesth 1996; 43(1t): 1085-9.

2. White PF. Clinical uses of intravenous anesthetic and analgesic infusions. Anesth Analg 1989; 68: 161-71.

3. Jones RM. Inhalation and intravenous anaesthetic agents. In: Nimmo WS, Smith G, editors. anaesthesia. 1st ed. Vol. 1. Oxford: Blackwell Scientific Publications; 1989. p.34-59.

4. Herbert M, Makin SW, Bourke JB, Hart EA. Post anaesthetic recovery: Recovery of mental abilities following general anaesthesia induced by propofol ('Diprivan') or thiopentone (abstract). Postgrad Med J 1985; 61 (Suppl 3); 132.

5. Lippmann M, Paicius R, Gingerich S, Owens R, Mok MS, Charney J, et al. A controlled study of the hemodynamic effects of propofol vs. thiopental during anesthesia induction (abstract). Anesth Analg 1986; 65: S89.

6. Taylor MB, Grounds RM, Mulrooney PD, Morgan M. Ventilatory effects of propofol during induction of anaesthesia: comparison with thiopentone. Anaesthesia 1986; 41: 816-20.

7. Smith I, White PF, Nathanson M, Gouldson R. Propofol: an update on its clinical use. Anesthesiology 1994; 81(4): 1005-43.

8. Inhalational induction of anaesthesia - New inspiration? (editorial). The Lancet 1986; 12: 84 .

9. Vitcha JF. A history of Forane (editorial). Anesthesiology 1971; 35(1): 4-7.

10. Bryce-Smith R, O'Brien HD. Fluothane: A non explosive volatile anaesthetic, agent. Br Med J 1956; 969-72.

11. Jones RM. Clinical comparison of inhalational anaesthetic agents. Br J Anaesth 1984; 56: 57S-69S

12. Modica PA, Tempelhoff R, White PF. Pro- and Anticonvulsant effects of anesthetics (Part I). Anesth Analg 1990; 70: 303-15.

13. Eger II El. The pharmacology of Isoflurane. Br J Anaesth 1984; 56: 71S-99S.

14. Wade JG, Stevens WC. Isoflurane: An anesthetic for the eighties? Anesth Analg 1981; 60(9): 666-82.

15. Smith I, Nathanson M, White PF. Sevoflurane a long awaited volatile anaesthetic. Br J Anaesth 1996; 76: 435-45.

16. Jones RM. Desflurane and sevoflurane: Inhalation anaesthetics for this decade? Br J Anaesth 1990;65: 527-36.

17. Wallin RF, Napoli MD. Sevoflurane (fluoromethyl - 1, 1, 1, 3, 3, 3 hexafluoro -2- propylether): a new inhalation anaesthetic agent (abstract). Fed Proceedings 1971; 30: 442.

18. Wallin RF, Regan BM, Napoli MD, Stern IJ. Sevoflurane: a new inhalational anaesthetic agent. Anesth Analg 1975; 54(6): 758-65.

19. Sebel PS, Lowdon JD. Propofol: a new intravenous anesthetic. Anesthesiology 1989; 71:260-77.

20. Yurino M, Kimura H. Induction of anesthesia with sevoflurane, nitrous oxide and oxygen: A comparison of spontaneous ventilation and vital capacity rapid inhalation induction (VCRII) techniques. Anesth Analg 1993; 76: 598-601

21. Yurino M, Kimura H. A comparison of vital capacity breath and tidal breathing techniques for induction of anaesthesia with high sevoflurane 
concentrations in nitrous oxide and oxygen. Anaesthesia 1995; 50: r,308-11.

22. Yurino M, Kimura H. Comparison of induction time and characteristics between sevoflurane and sevoflurane / nitrous oxide. Acta Anaesthesiol Scand1995; 39: 356-8.

23. Smith I, Ding Y, White PF. Comparison of induction, maintenance and recovery characteristics of sevoflurane - N20 and propofol - sevoflurane N20 with propofol - isoflurane - N20 anaesthesia. Anesth Analg 1992; 74: 253-9.

24. Hall JE, Stewart JIM, Harmer M. Single breath inhalation induction of sevoflurane anaesthesia with and without nitrous oxide: a feasibility study in adults and comparison with an intravenous bolus of propofol. Anaesthesia 1997; 52: 410-5.
25. Thwaites A, Edmends S, Smith I. Inhalation induction with sevoflurane: a double blind comparison with propofol. Br J Anaesth 1997; 78: 35661.

26. Dashfield AK, Birt DJ, Thurlow J, Kestin IG, Langton JA. Recovery characteristics using single breath $8 \%$ sevoflurane or propofol for induction of anaesthesia in day care arthroscopy patients. Anaesthesia 1998; 53: 1062-6.

27. Sivalingam P, Kandasamy R, Madhavan G. Dhakshinamoorthi P. Condition for laryngeal mask insertion: a comparison of propofol versus sevoflurane with or without alfentanii. Anaesthesia 1999; 54: 271-6.

28. Molloy ME, Buggy DJ, Scanlon P. Propofol or sevoflurane for laryngeal mask airway insertion. Can J Anesth 1999; 46: 322-6.

Copyright: () the author(s), publisher. Academia Anesthesiologica International is an Official Publication of "Society for Health Care \& Research Development". It is an open-access article distributed under the terms of the Creative Commons Attribution Non-Commercial License, which permits unrestricted non-commercial use, distribution, and reproduction in any medium, provided the original work is properly cited.

How to cite this article: Dasgupta S, Agrawal B, Rangari P. A Study to Evaluate Sevoflurane With or Without Nitrous Oxide and to Compare It with Propofol as Induction Agent- A Randomized Clinical Trial. Acad. Anesthesiol. Int. 2019;4(2):237-43.

DOI: dx.doi.org/10.21276/aan.2019.4.2.54 